\title{
Application of Discourse Interaction Data Analysis System in Teaching Evaluation for TCSOL
}

\author{
Fei Song \\ Beijing International Studies University, China
}

\begin{abstract}
With the development of the Chinese language teaching all over the world, there is an increasing demand for TCSOL. However, there is no pure data-driven and highly automated teaching evaluation mode so far. Hence the paper learn and improve Flanders' Interaction Analysis System, in order to establish a set of Discourse Interaction Data Analysis System (DIDAS) and selects a typical Lesson of volunteer Chinese teachers in the Confucius Institute to make confirmatory analysis, and finally proves that the system is workable for the teaching evaluation of TCSOL and is suitable for promoting their self-teaching evaluation, so as to achieve the purpose of enhancing teaching quality.
\end{abstract}

Index Terms - discourse interaction, TCSOL, teaching evaluation

\section{INTRODUCTION}

This paper tries to use the self-developed Discourse Interaction Data Analysis System (DIDAS) based on Microsoft Office Excel ${ }^{1}$ to study on the winning entry of the 1st International Volunteer Chinese Teachers Overseas Teaching Competition which was sponsored by Confucius Institute Headquarters (Hanban), and then to establish a quantitative evaluation mode of the teaching quality of TCSOL. Through numerous analyses of discourse interaction of TCSOL, we may know the general parameters of the excellent teachers, so that we can establish and improve the norms of discourse interaction and then establish a clear and effective classroom interaction self-checking system for TCSOL. In this way, we can improve the level of international Chinese language teachers' classroom teaching.

\section{A. Theoretical Foundation}

The theoretical foundation of this paper is Flanders' Interaction Analysis System (Flanders, 1970), which aims at establishing a statistic model for discourse interaction. The specific method applied is cutting class time into segments of 3 seconds and coding the discourse acts, then recording the classroom speech acts by their codes. Through statistical processing of the recorded codes, not only can we record and analyze the teaching acts of the teachers in teaching scenarios, manifest the structure, behavior pattern and style of classroom teaching, and providing the teachers with information for the improvements of their teaching, but also can we have a reference index for the evaluation of teaching quality. The advantages of Flanders' Interaction Analysis System is that it counts, analyzes and proceeds the discourse interaction between teachers and students in a quantified way, analyzes and reflects the teaching process with quantized data. Combined with qualitative descriptions about teaching by classroom observation, a comprehensive cognition and analyzation can be attained.

\section{B. Research Methods}

In terms of the scale of the database, given that each segment has 3 seconds, there should be 1,000 records in a class of 50 minutes. If more class time is involved, there shall be several thousands of records, and Excel can totally meet the need. In terms of computing demands, the research requires the programming of "pairing of records, duplicate record data detection, classifies counting, matrix transfer and data visualization" in order to realize data linkage. Using the function composition of Excel to replace programming makes a lower demand for the operators of the computer operating skills. Based on the above, Excel has been chosen as the method of this research. Analyzing the discourse interaction through Excel programming greatly improves the efficiency, for it avoids the possible mistakes that hand computation and matrix transfer may cause, and the system can be modified or expanded according to actual needs, which provides much convenience.

\section{Choice of Sample Class}

The sample class chosen in this paper is called "How many minutes does it take to walk to the hospital?", the language level of the target audience of this class is all primary. This class is an outstanding winner of the 1st International Volunteer Chinese Teachers Overseas Teaching Competition held by the Confucius Institute Headquarters

\footnotetext{
${ }^{1}$ The self-developed DIDAS based on MS Excel can be downloaded for free from https://pan.baidu.com/s/1nvOzcMl.
} 
(Hanban) during October 2011 and February 2012. The statistics show that the volunteer teachers of Confucius Institute are often confronted with students with low basics2, and most of the classes are comprehensive ones3, which mean the sample class here has universality in the present situation of TCSOL. And also, this is a class that beat 493 competitors and got the highest evaluation, thus the conclusion of discourse interaction analysis from it has certain referential and inspirational value.

\section{Quantifying Chart and Specified Standards}

As for the connotation and denotation of Flanders' Interaction Analysis System coding, there has been numerous of different points in the educational circles. The pre-research of this paper found that the differences between the points are not as great as to change the statistical meaning of Flanders' Interaction Analysis System, which means that as long as the connotation and denotation of the coding are made clear in the research process, the system shall reflect the discourse interaction objectively based on the certain given the connotation and denotation. It is just like a jigsaw of a map of the world, may it be the single units are in the shape of squares or right triangles, we can have a compact and complete map of the world as long as we do it in the proper way. Considering the realities of TCSOL class rooms, the specific coding system is as follows:

CHART 1:

DISCOURSE INTERACTION ANALYSIS CATEGORIES DEFINED

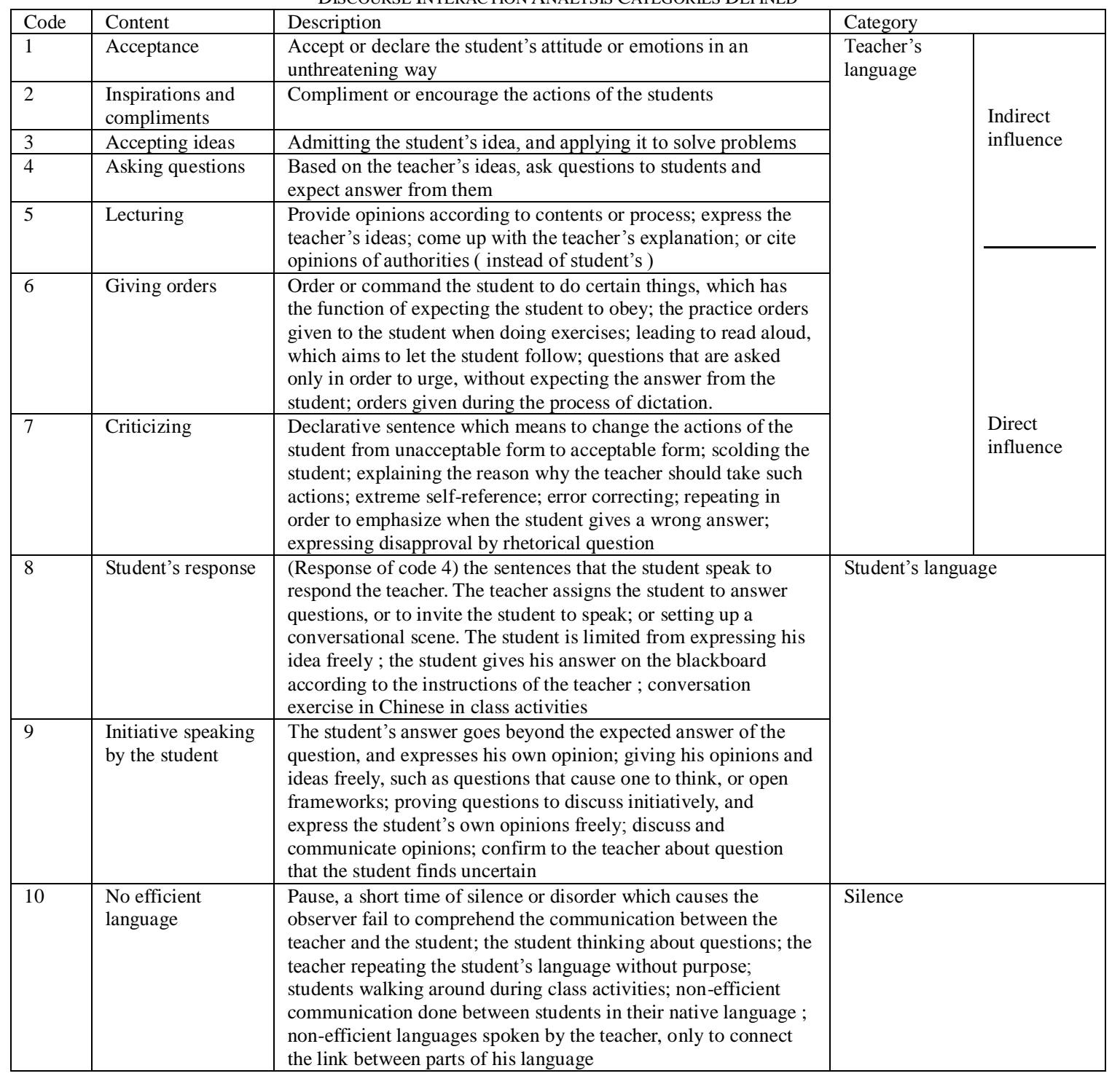

\section{The Process of Discourse ANALYZE}

\footnotetext{
2 There had been 61019 students in total attending the primary, senior, and advanced and university Chinese major classes of the Confucius Institute all over the world in 2010, among which 48434 took the primary Chinese class, which is $79.38 \%$ of all the students. (Data from http://tpi.muc.edu.cn). 3 There had been 3256 courses set up by the Confucius Institute all over the world in 2010, among which 2230 are comprehensive courses. (Data from http://tpi.muc.edu.cn).
} 


\section{A. Setting a Transfer Matrix}

Through repeatedly viewing the video of the class "How many minutes does it take to walk to the hospital?", and recording the class according to the defined Discourse Interaction Analysis Categories, we have this Interaction Analysis matrix (see chart below) through DIDAS.

CHART 2:

DisCOURSE INTERACTION ANALYSIS MATRIX OF THE SAMPLE Class

\begin{tabular}{|r|r|r|r|r|r|r|r|r|r|r|r|}
\hline & 1 & 2 & 3 & 4 & 5 & 6 & 7 & 8 & 9 & 0 & Total \\
\hline 1 & 0 & 0 & 0 & 0 & 0 & 0 & 0 & 0 & 0 & 2 & 2 \\
\hline 2 & 0 & 5 & 0 & 0 & 0 & 2 & 0 & 32 & 0 & 3 & 42 \\
\hline 3 & 0 & 0 & 0 & 3 & 0 & 0 & 0 & 0 & 0 & 0 & 3 \\
\hline 4 & 0 & 3 & 0 & 10 & 13 & 8 & 3 & 25 & 0 & 14 & 76 \\
\hline 5 & 0 & 15 & 0 & 3 & 174 & 16 & 0 & 16 & 0 & 15 & 239 \\
\hline 6 & 1 & 14 & 0 & 13 & 20 & 142 & 2 & 66 & 0 & 28 & 286 \\
\hline 7 & 0 & 0 & 0 & 0 & 0 & 0 & 0 & 13 & 0 & 1 & 14 \\
\hline 8 & 0 & 5 & 5 & 39 & 12 & 85 & 6 & 206 & 0 & 28 & 386 \\
\hline 9 & 0 & 0 & 0 & 0 & 0 & 0 & 0 & 0 & 0 & 0 & 0 \\
\hline 0 & 0 & 5 & 1 & 7 & 19 & 34 & 0 & 23 & 0 & 68 & 157 \\
\hline Total & 1 & 47 & 6 & 75 & 238 & 287 & 11 & 381 & 0 & 159 & 1205 \\
\hline
\end{tabular}

In the shadowed boxes in the matrix, the number 0 to 9 respectively stands for the ten kind of discourse interactions showed in chart 1 Discourse Interaction Analysis Categories. In the unshaded boxes the numbers stand for the times that the actions in the X-axis occur first and then the actions in the Y-axis occur next in every 6 seconds.

\section{B. Research on Classroom Structures}

Through the statistics in chart 2, we can get the classroom structure data as follows:

CHART 3:

Class STRUCTURE DATA OF THE SAMPLE Class

\begin{tabular}{|l|l|l|}
\hline Category & Mean of Computing & Rate \\
\hline Rate of teacher's language & Numbers in $1^{\text {st }}$ row to $7^{\text {th }}$ row/total & $55.1168 \%$ \\
\hline Rate of student 's language & Numbers in $8^{\text {th }}$ row to $9^{\text {th }}$ row/total & $31.9903 \%$ \\
\hline Rate of non-efficient language & Numbers in $10^{\text {th }}$ row/total & $12.8928 \%$ \\
\hline Rate of teacher's questions & Numbers in $4^{\text {th }}$ row $/$ numbers in $4^{\text {th }}$ row to $5^{\text {th }}$ row & $24.6057 \%$ \\
\hline Rate of teacher's language-student driven & $\begin{array}{l}\text { Numbers in } 1^{\text {st }} \text { row to } 3^{\text {rd }} \text { row } / \text { numbers in } 1^{\text {st }} \text { row to } 3^{\text {rd }} \text { row plus } \\
\text { numbers in } 6 \text { the row to } 7^{\text {th }} \text { row }\end{array}$ & $31.0112 \%$ \\
\hline $\begin{array}{l}\text { Rate of student's language-student } \\
\text { initiative }\end{array}$ & Numbers in $9^{\text {th }}$ row $/$ numbers in $8^{\text {th }}$ row to $9^{\text {th }}$ row & $2.2670 \%$ \\
\hline
\end{tabular}

\section{(1) Rate of teacher's language}

As it is shown in chart 3, the rate of teacher's language in this class is $55.1168 \%$, which is lower than the average rate of 68\% (Qi Hua., \& Li Wen, 2009). Through large amount of research, American educationalist Belek put forward his conclusion that "the teacher dominates the language activities in the class. According to the record on audio tape, the proportion of teacher's and student's activities is 3:1. Thus, putting away the unit of analysis, the amount of teacher's language activity is far more active than that of the student's." (Gao W, 2009). In the sample class chosen in this paper, the proportion of teacher's and student's activities is roughly 2:1. The rate of teacher's language is far lower than the result shown in Belek's research, which means that the teacher have properly controlled his language in amount, providing the students with more chances to participate.

\section{(2) Rate of student's language}

The rate of student's language in this class is $31.9903 \%$, which is higher than the average rate of $20 \%$ (Qi Hua., \& Li Wen, 2009), which means that as the teacher properly controlled his language in amount, the students had more chances to speak in class, and thus had more opportunities to practice their language abilities.

\section{(3) Rate of non-efficient language}

The rate of non-efficient language in this class is $12.8928 \%$, which is slightly higher than the average rate of $12 \%$ (Qi Hua., \& Li Wen, 2009), which means that there was relatively more "vacant time". Through studying the video record, we found that this was mainly due to the lack of fluency in Chinese expression of the beginners. It is normal that the rate of non-efficient language rises in moderation. However, the teachers should pay more attention to this and lower the non-efficient language rate while rise the efficiency of the class by fully preparation and proper arrangement of class time.

\section{(4) Rate of teacher's questions}


This rate stands for the frequency of the teacher using questions to lead a discussion. The rate of teacher's questions of this class is $24.6057 \%$, which is slightly lower than the average rate of $26 \%$ (Qi Hua., \& Li Wen, 2009). This means that in this class the teacher seldom uses questions to lead discussions. Compared with senior and advanced TCSOL classes, this is a marked feature in primary TCSOL classes, and is something that teachers should lay more stress on. Letting the students discuss, communicate and explore on their own is not only beneficial for the active minds and independent exploring abilities of the students, but also helpful for their study and research abilities in the future.

\section{Study on the Teacher's Tendencies}

Through the statistics in chart 2, we can have data about teacher's tendencies as follows:

CHART 4:

TEACHER's TENDENCIES DATA OF THE SAMPLE CLASS

\begin{tabular}{|l|l|l|}
\hline Category & Mean of Computing & Rate \\
\hline Rate of indirect influence and direct influence & $\begin{array}{l}\text { Numbers in } 1^{\text {st }} \text { row to } 3^{\text {rd }} \text { row/numbers } \\
\text { in } 5^{\text {st }} \text { row to } 7^{\text {th }} \text { row }\end{array}$ & $25.2747 \%$ \\
\hline Rate of positive influence and passive influence & $\begin{array}{l}\text { Numbers in } 2^{\text {nd }} \text { row to } 3^{\text {rd }} \\
\text { row/numbers in } 6^{\text {th }} \text { row to } 7^{\text {th }} \text { row }\end{array}$ & $19.2182 \%$ \\
\hline
\end{tabular}

\section{(1) Rate of indirect influence and direct influence}

We can see in the chart above that the rate of indirect influence and direct influence is $25.2747 \%$. Although there is no average data for us to refer to up to now, we can still infer that the time the teacher spends on accepting student's ideas, expressing his own opinions, complimenting student and leading the student by putting forward questions is far less than the time he spends on giving lectures, giving orders and correcting the errors the students make while answering questions. Thus the teacher tends to have direct control over the teaching activities and the students.

\section{(2) Rate of positive influence and passive influence}

In this sample class, the rate of positive influence and passive influence is $19.2182 \%$, which means that in the teaching process the teacher mainly emphasized his points by passive means. The passive means here refers to the error correction by the teacher, instead of criticizing. For the beginners of Chinese learning, they often make more mistakes when trying to answer a question, and a responsible TCSOL teacher should correct their mistakes timely. When affirming an answer by the student, the teacher usually uses relatively simple language because he is hurrying to start the next part, which made this rate even lower. However, if such situation lasts for too long during a class, the students may start to become frustrated and fatigued, and then become afraid of the difficulty. Thus it is important for a teacher to properly control the atmosphere of the class, and restrain the students from such passive emotions.

\section{Study on Classroom Emotions Atmosphere}

Through the statistics in chart 2, we can have data about classroom emotions atmosphere as follows:

CHART 5:

ClassRoom EMOTIONS ATMOSPHERE DATA OF THE SAMPLE CLASS

\begin{tabular}{|l|l|l|}
\hline Category & Means of Computing & Rate \\
\hline Rate of positive integrate & Times of positive integrate/ total & $0.4029 \%$ \\
\hline Rate of defect & Times of defect/ total & $11.6841 \%$ \\
\hline Rate of the crossing area of contents & Times of crossing area of contents / total & $32.72 \%$ \\
\hline
\end{tabular}

\section{(1) Rate of positive integrate}

As it is known to us, positive integrate boxes are the nine boxes in the crossing area of row1 t row 3 with line 1 to line 3, thus this area's proportion in all the 100 boxes is $9 \%$. But we can see from the chart above that the rate of positive integrate in this class is only $0.4029 \%$, which means that in the class the teacher failed to emphasize and encourage the students to take the initiative to speak. As we have mentioned previously, the teacher tends to have his control over the classroom.

\section{(2) Rate of defect}

Defect boxes are the four boxes in the crossing area of row6 t row 7 with line 6 to line 7 , thus this area's proportion in all the 100 boxes is $4 \%$. We can see in the chart above that the actual rate of defect in this class is $11.6841 \%$, which is higher than the average rate. Usually this data infers that the teacher has taken the most control over the classroom, and has criticized over students, while there are discipline problems. However in the sample class, most defect boxes fall into $(6,6)$, and this reflects that the reason for the high rate of defect is that the teacher guides the students to practice through giving continuous orders, instead of criticizing the students or emphasizing the discipline. This kind of situation occurs frequently for a TCSOL teacher with systematic training.

\section{(3) Rate of the crossing area of contents}

The rate of the crossing area of contents includes the crossing area of row 4 to row 5 and line 4 to line 5 , thus this area's proportion in all the 100 boxes is $36 \%$. If most statistics concentrate on this area, it infers that in the class the teacher mainly uses methods like asking questions and giving lectures to teach. Generally speaking, this is the most applied teaching method by teachers now. However, few teachers with higher flexibility are different. Shown on the chart, there would be more data falling in area other than the crossing zone. In this sample class, The rate of the crossing 
area of contents is $32.72 \%$, leaving relatively large number of data outside the crossing area, which reflects that the teacher is relatively flexible in terms of applying teaching methods.

\section{E. Analysis on Discourse Interaction Patterns}

Flanders' interaction patterns include "question and answer" and "inspiring questions". The "question and answer" pattern includes the data in the four boxes of $(4,4),(4,8),(8,4),(8,8)$ (the boxes shaded in dark blue in chart 2), while the "inspiring questions" includes the data in the eight boxes of $(9,9),(9,3),(3,3),(3,9)$ and $(8,3),(4,9),(8,9),(4,3)$, (the boxes shaded in light blue in chart 2).

\section{(1) "Question and answer" pattern}

In this sample class, the frequencies of codes of $(4,4),(4,8),(8,4),(8,8)$ are $10,39,25,206$ respectively. The highest frequency appears in $(8,8)$, which means that in this class the "question and answer" followed the pattern of $(8$, 8 ), which stands for the pattern of students continuously answering the questions put forward by the teacher. The frequency of this pattern goes far beyond than those of other patterns, and this means that the questions by the teacher are relatively short, and got relatively long answers from the students, not brief answers like "yes" or "no". Class time have been made good use of, the students have been provided with plenty of opportunities of practicing their oral Chinese and expressing their own opinions, but there have been a lack of trace and extend. Here we can see that in this class the patterns of discourse interaction are still yet to be diversified. Although the $(8,8)$ pattern which encourages the students to speak more are worth advocating, the rate of $(8,4)$ should also be increased.

\section{(2) "Inspiring questions" pattern}

In this sample class, the frequencies of codes of $(9,9),(4,9),(8,3),(4,3)$ are $8,1,7,3$ respectively. This reflects that in this class the students have both initiative and continuous language acts and freely expressing language acts instead of immediate answer after a question by the teacher; while the teachers have both acts like immediate affirm, clear or extend to the students answer and acts like explaining a question with student's opinions instead of letting other students to answer them. Generally speaking, however, the applying of "inspiring questions" is still very limited, and the frequencies of codes of $(9,3),(3,3),(3,9),(8,9)$ are all 0 , which means these kinds of "inspiring questions" was not applied in this class, although they have great importance for the development of creativity and questioning spirit of the students. Thus it can be seen that these are the fields that need to be improved in the future.

\section{F. Dynamic Characteristic Curve}

We can have a systematic and visual observation of the changing trends of the main data in the class by analyzing and computing the main data in DIDAS in the units of one minute and drawing the dynamic characteristic curve:

GRAPH 1:

THE DYNAMIC CHARACTERISTIC CURVE OF THE SAMPLE Class

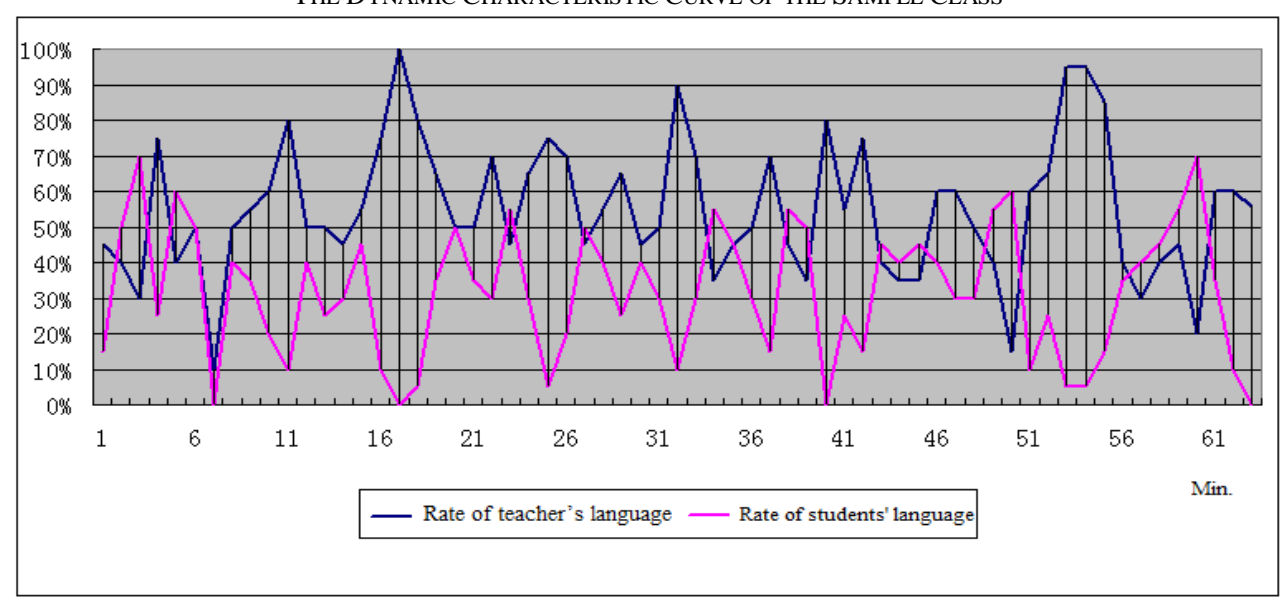

The blue curve and the pink curve are the dynamic characteristic curve of the rate of teacher's language and the rate of student's language respectively. We can see it clearly from the graph the trends and rhythms of their languages.

\section{G. The Inspiration of the sample Class on TCSOL Evaluation}

The inspirations through the analysis of the sample class on TCSOL evaluation are as follows:

First, in terms of the structures of the class, excellent TCSOL should properly add the chances for the student to speak, reduce the rate of teacher's language and avoid non-efficient languages through his outstanding ability of controlling over the classroom. Based on that the teacher could grasp the student's Chinese language ability levels well, he should lead discussions more with questions. However, if the rate of teacher's questions and non-efficient languages rise at the same time, the teacher should reconsider his question's qualities.

Second, in terms of the teacher's tendencies, under the condition that the TCSOL teacher has a proper control over the classroom, the practicing and error correcting acts will still reduce the rate of positive influence and passive 
influence and rate of indirect influence and direct influence. If these two rates go too low, the teacher should be noticing that he might be taking too much control over the class and leaving little space for the students to exert their initiative.

Third, in terms of the classroom atmosphere, the rate of positive integrate should not go too high, or else the classroom tend to go too relaxed, while practicing and error correcting acts gives rise to the rate of defect. The teacher should properly deal with the relationship between these two rates in order to build a relatively concentrated and active classroom atmosphere.

Fourth, in terms of discourse interaction patterns, a TCSOL teacher should try to avoid the "question and answer" pattern of $(4,4)$, for that this reflects the lack of concision and precision if the questions by the teachers, while the "question and answer" pattern of $(8,8)$ usually means that the students are provided with plenty of opportunities of practicing their oral language.

Fifth, in terms of the dynamic characteristic curve, the swing of the curve should not be too fierce and the vibrational frequency should not be too low, for this reflects that there is a lack of discourse interaction, and the classroom is not active enough.

\section{CONCLUSION}

The DIDAS provides a brand-new, quantified angle of view for the research on TCSOL's ability levels, and it can be applied widely into teaching evaluations for TCSOL.

Firstly, it makes the evaluation for TCSOL objective, scientific and operative. The DIDAS emphasizes the observation of the discourse interaction acts between the students and the teachers, and uses "code" to record the facts in class, thus fully reflecting the teacher's language acts and students' response. When it comes to the processing method and applying of results, the DIDAS visualizes the complicated teaching process, avoids the subjectivity and randomness of traditional teaching evaluation, and greatly improves the objectiveness and scientificalness of the process. And at the same time, sue to its high operability and semi-automatic analyzing character, it has great potential of popularizing, for it can be widely used for the general teaching evaluation for TCSOL.

Secondly, it is a method of self-evaluation for teachers. The teachers could record their teaching process without the help of a third person who might cause changes of the classroom circumstance. And also, teachers usually have no time to reflect their own teaching in the middle of a class, and viewing the record of their own classes, their evaluation could be influenced by their subjective emotions. DIDAS provides the teacher with a tool to get objective data about their performance, through which they can reflect their teaching activity, analyze their teaching language, realize their teaching method, thus improving their language style, controlling the steps of teaching, finding problems of their classes timely, and finally reaching the goal of enhancing their teaching performance.

Lastly, the norms of TCSOL discourse interaction should be built. Due to the differences between types of classes, the norms by previous researches may not be suitable for TCSOL class, thus it is necessary that we do research widely using this method and finally establish norms which suit for the TCSOL class. The establishing of the norms will further promote the applying of this system in TCSOL class.

\section{REFERENCES}

[1] Gao Wei. (2009). Research on discourse interaction between teacher and students. Educational Research and Experiment, 5, 43-49.

[2] Ned A Flanders. (1961).Analyzing Teacher Behavior:as part of the teaching learning process. Educational Leadership, 3(19): 173-200

[3] Ned A Flanders. (1963). Intent, Action and Feedback: A Preparation for Teaching. Journal of Teacher Education, 3(14): $25-260$.

[4] Ned A Flanders. (1970). Analyzing teaching behavior. Boston, MA: Addison-Wesley Educational Publishers Inc.

[5] Qi Hua. \& Li Wen. (2009). Interaction model of discourse in intermediate and advanced level in PIB, Journal of Beijing Normal University (Social Sciences), 6, 111-118.

Fei Song was born in Linyi, China in 1986. He received his PH.D. degree in linguistics from Minzu University of China in 2015.

$\mathrm{He}$ is currently a lecturer in the Chinese Academy, Beijing International Studies University, Beijing, China. His research interests include natural language processing and cognitive linguistics.

Dr. Song is a member of the Association for Modernization of Chinese Language Education. 